\title{
Antioxidants based on fatty acids
}

Oléagineux, Corps Gras, Lipides. Volume 8, Numéro 1, 89-91, Janvier - Février 2001, Dossier : Deutsche Gesellschaft für Fettwissenschaft - Association française pour l'étude des corps gras

Auteur(s) : Christian KALK, Hans J. SCHAEFER, Westfaelische Wilhelms-Universitaet, Corrensstr. 40, D-48149 Muenster, Germany.

Summary : Autoxidation is the cause for deterioration of organic materials. Many commercial products react with atmospheric oxygen under loss of quality. To retard unwanted oxidative damage and to prolong the useful life of the substrates, antioxidants are used to protect the organic matter. We linked phenolic compounds with fatty acids to obtain fatty acid conjugates with antioxidative action. The conjugates have a similar constitution like hindered phenols e.g. tert.-butyl-hydroxyanisole (BHA) and show good antioxidative action in the Rancimat-test. Ascorbic acid is an antioxidant and a strong reducing agent. Its action is based on a ketoene-diol structure. We were able to insert an analogous structure into a fatty acid chain. The products we obtained have similar oxidation potentials as ascorbic acid

Keywords : antioxidants, fatty acids, phenolic compounds, ascorbic acid, reducing agent.

Résumé : L'auto-oxydation est la cause de la dégradation des substrats organiques. Beaucoup de produits commerciaux réagissent avec l'oxygène de l'atmosphère, ce qui se traduit par une diminution de leur qualité. Pour retarder l'action dégradante de l'oxygène et préserver la structure des produits, l'emploi d'antioxydants pour protéger la matière organique est très répandu. Nous avons associé des composés phénoliques avec des acides gras afin d'obtenir de nouveaux acides gras " conjugués " ayant une action antioxydante. Ceux-ci ont une structure similaire au tertio-butylhydroxyanisol (BHA) et présentent une très grande activité antioxydante comme dans le cas du test Rancimat. L'acide ascorbique est un antioxydant et un agent réducteur très puissant. La structure céto-ène-diole est responsable de cette activité. Nous avons pu insérer une structure analogue dans une chaîne d'acide gras. Les produits que nous avons ansi obtenus ont une propriété oxydante semblable à celle de l'acide ascorbique.

Mots-clés : antioxydants, acides gras, composés phénoliques, acide ascorbique, agent réducteur. 


\section{ARTICLE}

Antioxidants are used in many commercial products to prevent oxidative damage. To suppress autoxidation is important to plastics, fuels, hydraulic liquids, and of course to food, feed, cosmetics and pharmaceutical products.

Linoleic acid $[\mathrm{LA}]$ is a natural occurring double unsaturated fatty acid, which is very sensitive against oxygen due to its chemical constitution. This oxidation occurs in a radical chain process as shown in Figure $1[1]$.

A possibility of suppressing autoxidation is the addition of reducing agents e.g. ascorbic acid. Reducing agents react with atmospheric oxygen and thus diminish the damage of products. Another possibility of suppressing autoxidation is the addition of radical trapping antioxidants, so called inhibitors. Inhibitors like tocopherols or hindered alkyl phenols are able to transfer a hydrogen radical to a chain-carrying peroxy radical. The resulting radicals are too stable to propagate the chain reaction [2].

\section{Fatty acids linked with phenolic compounds}

Linking a natural fatty acid to a phenolic compound should yield products which have a similar structure as hindered alkyl phenols e.g. tert.-butyl-hydroxy-toluene (Figure 2). Therefore these fatty acid derivatives should show similar antioxidative action.

To obtain such fatty acid conjugates we linked phenolic compounds to oleic acid by a Claisenrearrangement (Figure 3). The rearrangement of aryl allyl ethers leads to conjugates with a covalent and stable carbon-carbon bond between the phenol and the fatty acid.

In our synthesis of the aryl allyl ethers we investigated two ways to link the phenolic compounds to oleic acid. In the first way we used a Mitsunobu-reaction, in the second we prepared the precursor of the Claisen-rearrangement by a palladium (0)-catalysed reaction (Figure 4).

The yields (based on purified products) of the aryl allyl ethers and of the fatty acid conjugates are shown in Table 1 and 2.

The antioxidative efficacy of the fatty acid-phenol conjugates was determined by using the standardized Rancimat-test. [3] For that purpose samples of purified methyl oleate were heated up to $120^{\circ} \mathrm{C}$. The airflow was about 20 liters per hour per sample. In each case, we added $0.1 \mathrm{~mol} \%$ of inhibitor. Some of the results are shown in Figure 5.

To assess the quality of the fatty acid conjugates, we have compared some of them with commercial inhibitors. As can be seen the performance of the conjugates is of the same order as that of alphatocopherol (Figure 6).

\section{Fatty acid derivatives with an diene-dioxy structure}

Ascorbic acid is a well known and commonly used antioxidant. The antioxidative action is based on its oxygen trapping and reducing properties (Figure 7). The oxidation potential of ascorbic acid is about $0.49 \mathrm{~V}$ due to the keto-ene-diol structure [4]. 
Fatty acid derivatives with a diene-dioxy structure should have similar reducing properties. Ricinoleic acid methyl ester was used as starting material (Figure 8).

Ricinoleic acid was transformed into a diene diol diether and a hydroxy enone (Figure 8). The hydroxy enone forms an equilibrium with a tautomeric diene diol form. The proton NMR spectrum clearly revealed the existence of both isomers and indicated a ratio of 40 to $60 \%$ in $\mathrm{CDCl}_{3}$ as solvent with the diene diol as major component.

The oxidation potentials of the fatty acid derivatives were determined by cyclic voltammetry, which is a common method to characterize the ease of electron release [5]. The cyclovoltammogram of the diene diol diether, its oxidation potential as well as these of the diene diol and of ascorbic acid are shown in Figure 9. As can be seen, the fatty acid derived diene-dioxy compounds show oxidation potentials of the same order as ascorbic acid.

\section{CONCLUSION}

Different phenols have been covalently connected via their aryl ethers and a subsequent Claisenrearrangement to methyl oleate. These fatty acid-phenol conjugates have been examined with the Rancimat-test with regard to their antioxidative efficacy. It is of the same order as that of alphatocopherol.

The diene dioxy structure, that causes the reducing ability of ascorbic acid has been inserted into ricinoleic acid by either oxidation with singlet oxygen or by epoxidation. The oxidation potentials, that reflect the ease of electron release, of the fatty acid derived diene dioxy compounds are of the same order as that of ascorbic acid.

\section{Acknowledgements}

This work has been supported by the minister of agriculture and forestry of the Federal Republic of Germany. The Rancimat-test has been assisted by Mr Thorsten B

\section{REFERENCES}

1. HAMILTON RJ (1997). Rancidity in Foods. London: Blackie A \& P.

2. BURTON GW, INGOLD KU (1986). Vitamin E, Accounts of Chemical Research,19: 194-201.

3. LAEUBLI MW, BRUTTEL PA (1986). Determination of the oxidative stability of fats and oils. J Am Oil Chem Soc, 63: 792-5.

4. HEIMANN W, WISSER K (1962). Ueber das Redox-Verhalten der Ascorbinsaeure. Justus Liebigs Annalen der Chemie, 653: 23-32.

5. SCHAEFER HJ (1987). C-C Verknuepfungen und Umfunktionalisierungen an der Elektrode. Kontakte (Merck, Darmstadt): 17-31. 
Illustrations

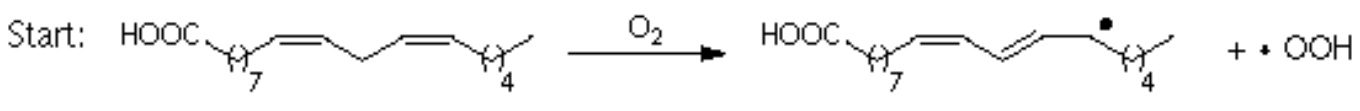
Linoleic acid [LA] Linoleic acid radical [LA *

Chain growth: $\mathrm{HOOC}_{7}=\mathrm{O}_{2}^{4}$

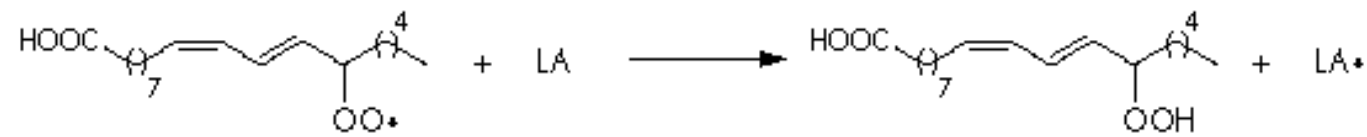

Decomposition of $\mathrm{HOOC}_{\text {hydroperoxides: }}=\left.\right|_{\mathrm{OH}} ^{\text {Acids }}$ Aldehydes
Alkenes

Figure 1. Autoxidation of linoleic acid [LA].<smiles>CC(=O)OC=CC(C(C)=O)c1cc(C)ccc1O</smiles>

Figure 2. Hindered alkyl phenol and fatty acid connected to a phenol. 


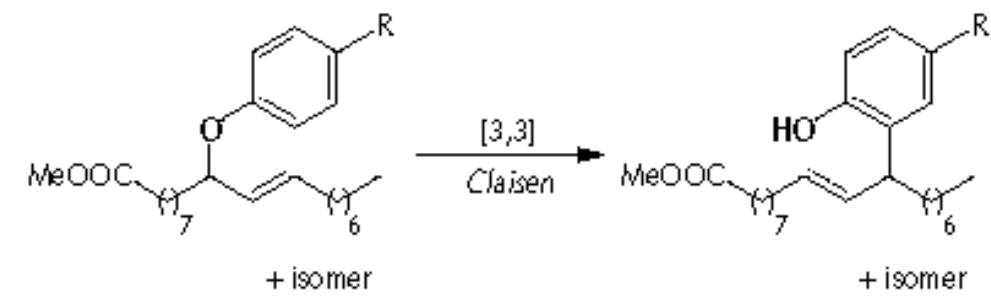

Figure 3. Claisen-rearrangement of aryl allyl ethers.

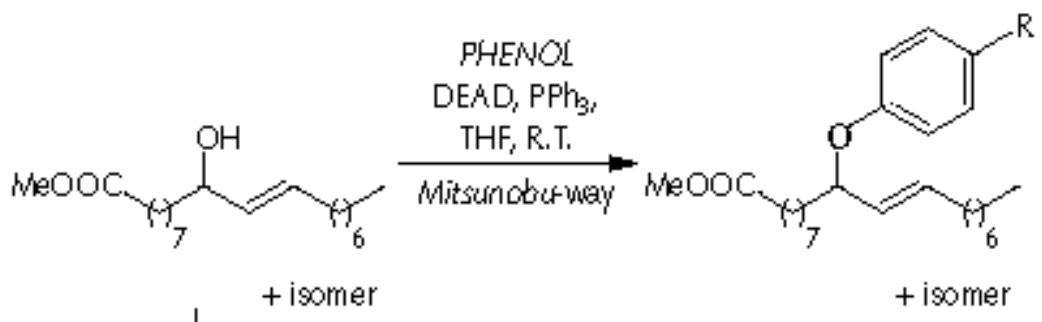

ClooOMe, pyr., $\mathrm{CH}_{2} \mathrm{C}_{2} ; 72 \%$

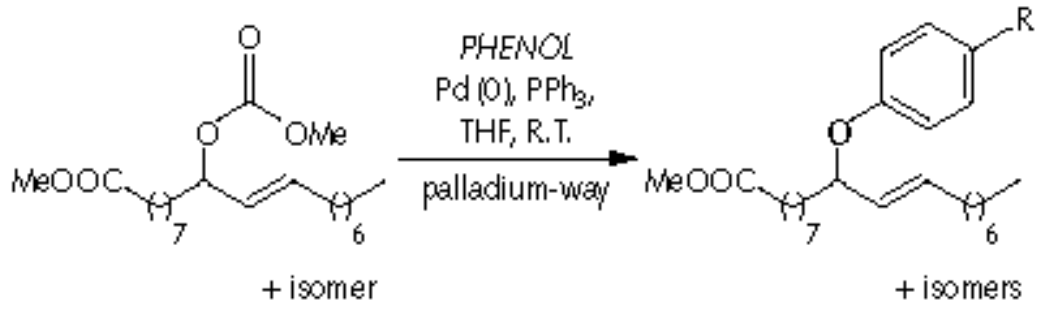

Figure 4. Synthesis of aryl allyl ethers. 


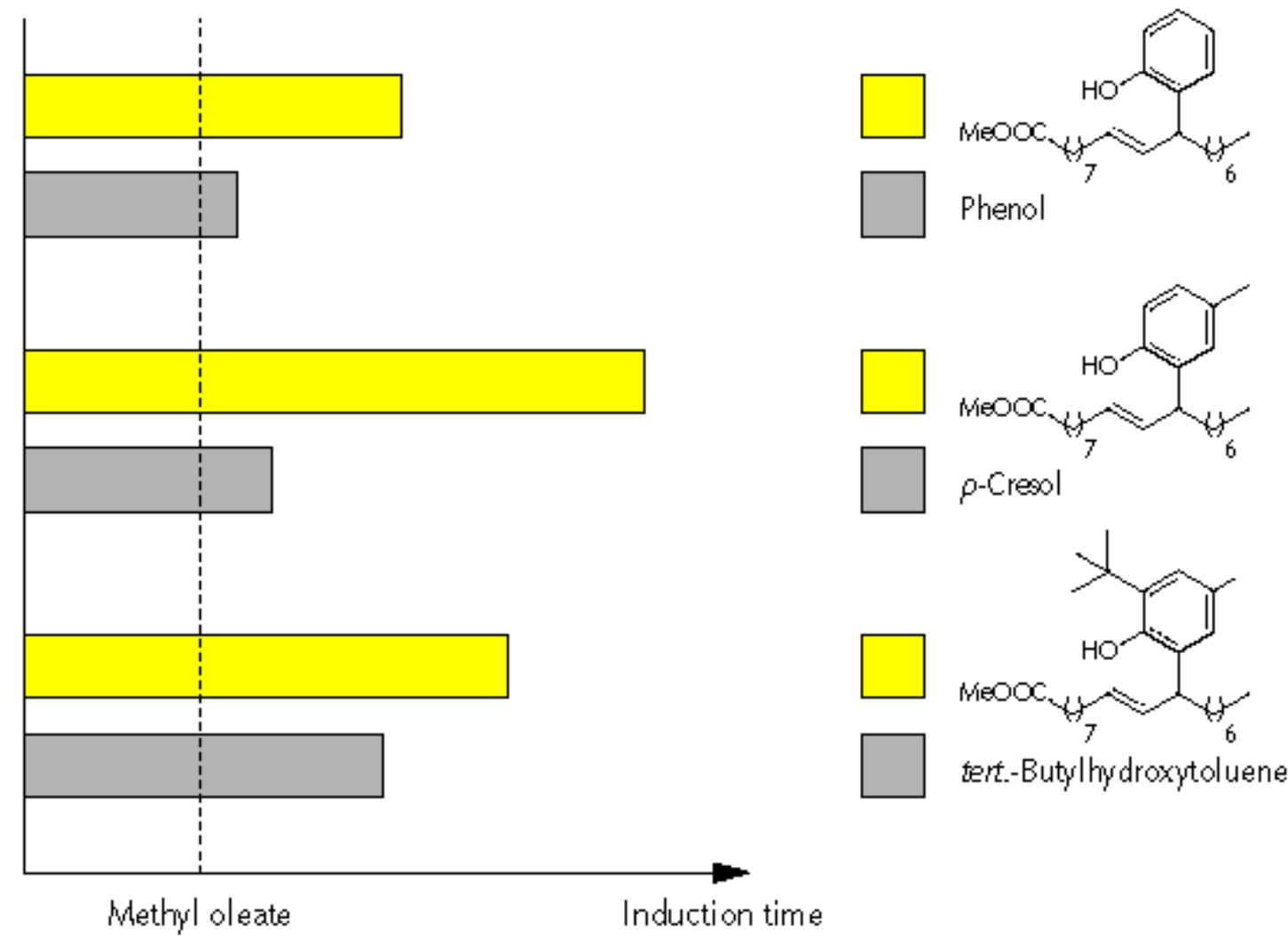

Figure 5. Determination of the antioxidative efficacy using the Rancimat-test. 

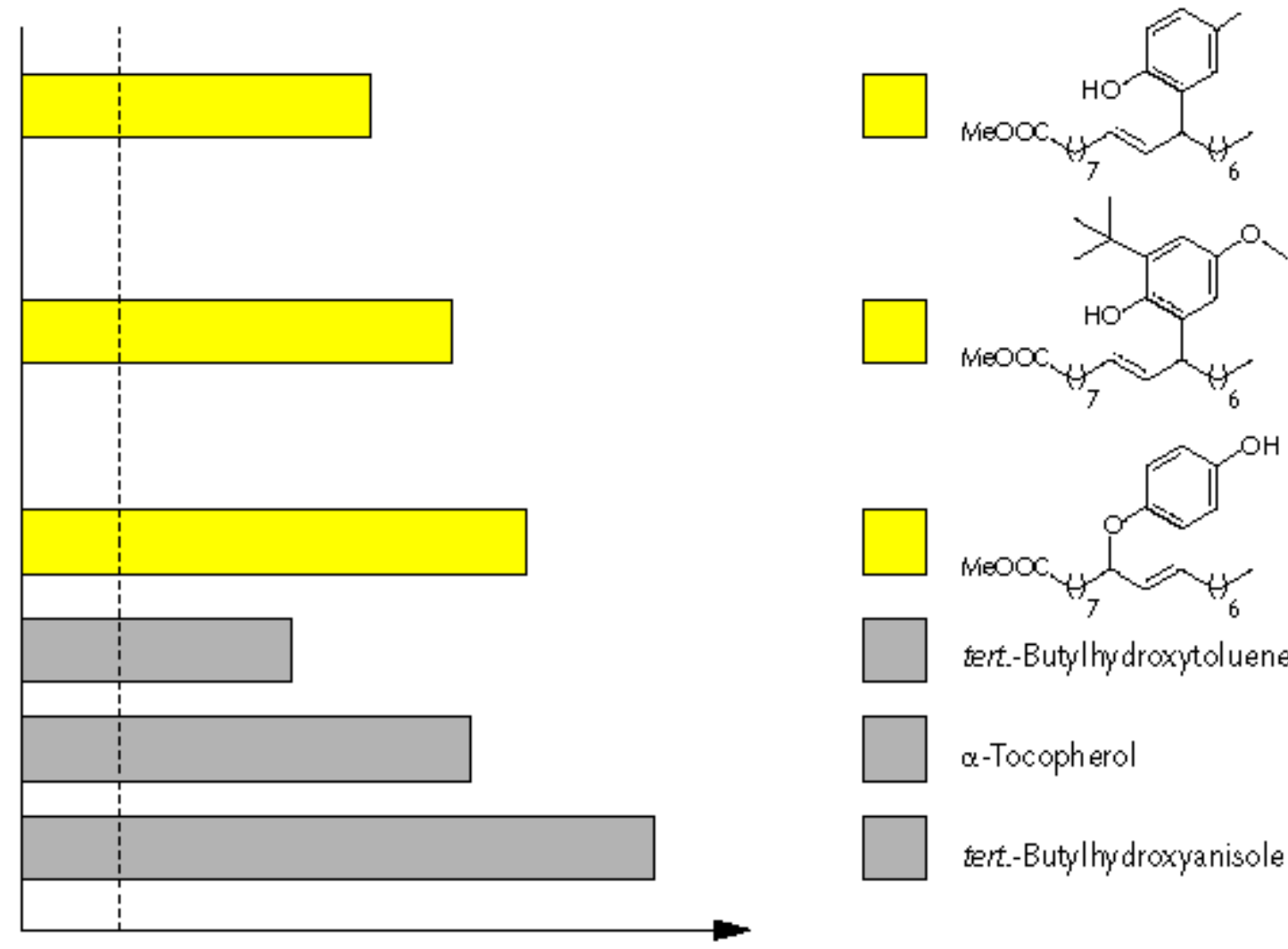

tert.-Butyllhydroxytoluene

$\alpha$-Tocopherol

tert.-Butylhydroxyanisole

Figure 6. Antioxidative efficacy of fatty acid conjugates (yellow) compared with commercial inhibitors (grey).<smiles>C=C[PH3+]</smiles>

Ascorbic acid<smiles>O=C1OC(C(O)CO)C(=O)C1=O</smiles>

Dehydroasoorbic acid

Figure 7. Reducing behaviour of ascorbic acid. 
<smiles></smiles>

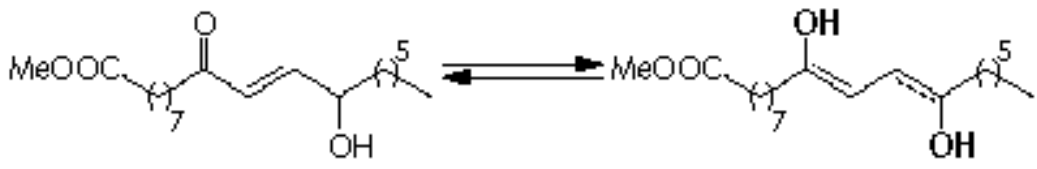

a: $\mathrm{We}_{3} \mathrm{OBF}_{4}, \mathrm{Me}_{2} \mathrm{Nb}_{2} \mathrm{C}_{10} \mathrm{H}_{6}, \mathrm{CH}_{2} \mathrm{Cl}_{2}, 80 \%$

b: $\mathrm{O}_{2}, \mathrm{hu}, \mathrm{TPP}, \mathrm{AC}_{2} \mathrm{O}, \mathrm{DMMAP}, \mathrm{pyr}_{\mathrm{r}}, \mathrm{CH}_{2} \mathrm{Cl}_{2}, 86 \%$

d: $\mathrm{PCC}, \mathrm{CH}_{2} \mathrm{Cl}_{2}, 85 \%$

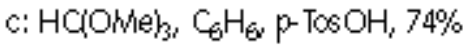

e: $\mathrm{m}-\mathrm{CPBA}, \mathrm{NaHCO}{ }_{3}, \mathrm{CH}_{2} \mathrm{Cl}_{2}$

f: $\mathrm{Al}_{2} \mathrm{O}_{3}, \mathrm{EtOAC}, 75 \%$ (e and f)

Figure 8. Synthesis of fatty acid derivatives with diene-dioxy structure.

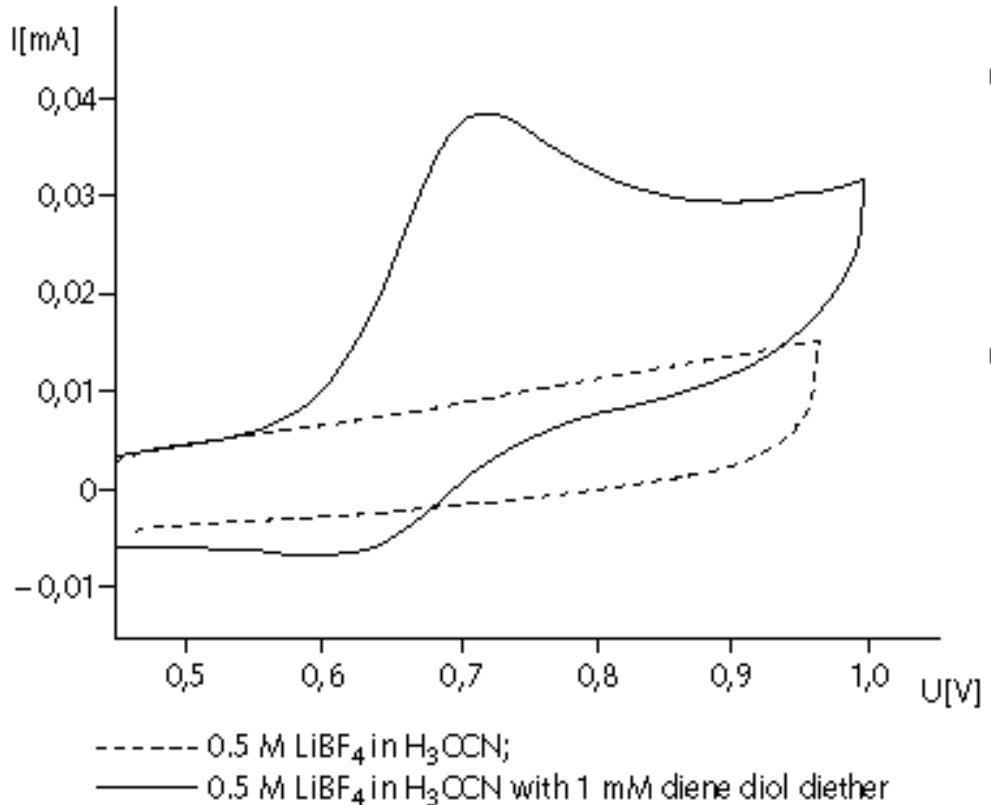<smiles>COC(=O)/C(C)=C/C=C(/OC)C(C)=O</smiles>

$0.700 \mathrm{~V}$<smiles>CC(=O)C(O)=CC=C(O)C(C)C</smiles>

$0.680 \mathrm{~V}$<smiles>COC(=O)OCC(O)C1OC(=O)C(O)=C1O</smiles>

Figure 9. Cyclovoltammogram and oxidation potentials (vs $\mathrm{Ag} / \mathrm{AgCl}$ ) of fatty acid derived diene dioxy compounds and of ascorbic acid. 


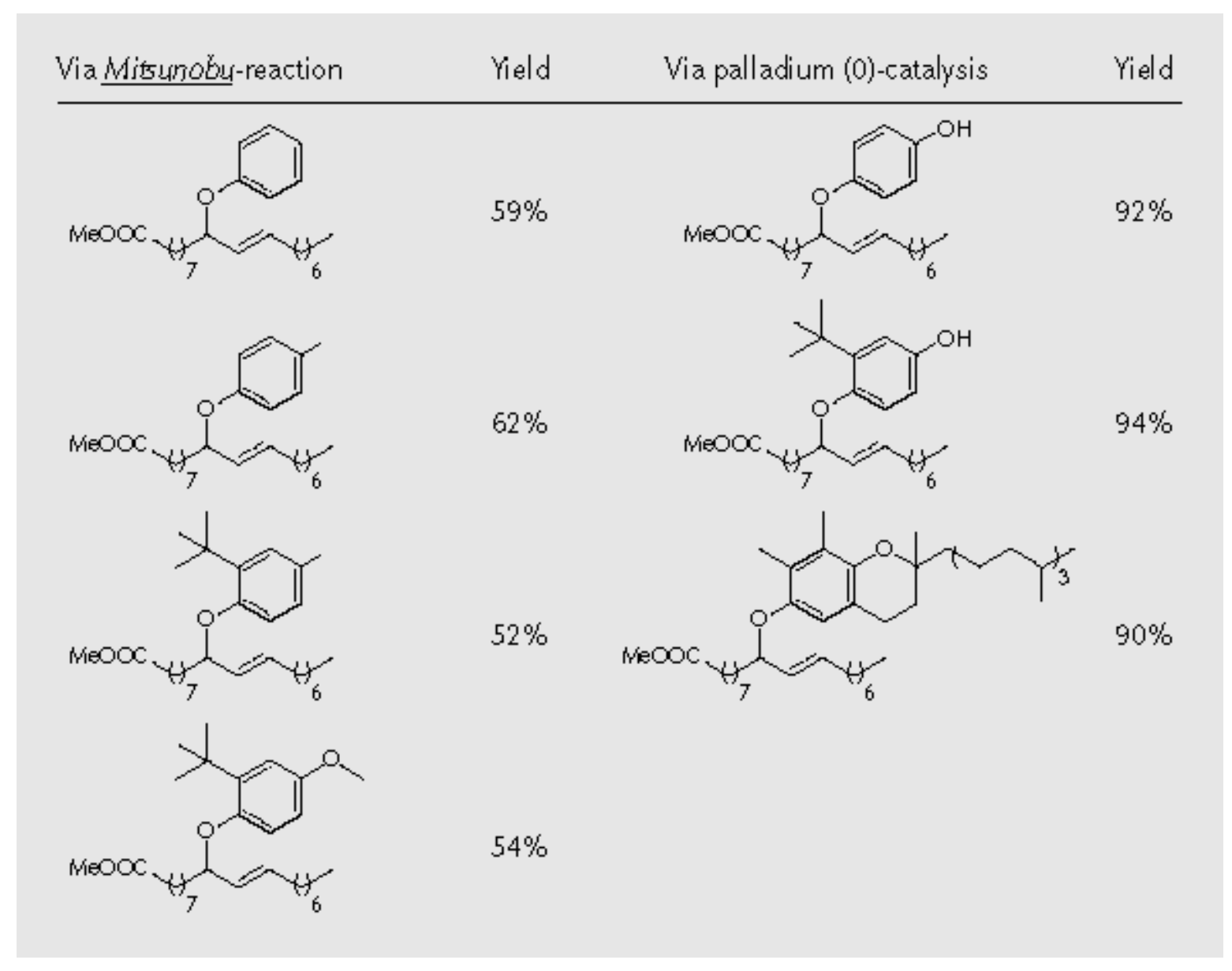

Table 1. Synthesis of aryl allyl ethers. 
<smiles>CC(=O)OCC=C(C)c1ccccc1O</smiles><smiles>COc1cc(C(C=CCC(C)=O)C=CC(C)=O)c(O)c(C(C)(C)C)c1</smiles><smiles>CCC(C=CCC(C)=O)c1cc(C)ccc1O</smiles>

$90 \%$<smiles>CC(=O)CCCCC1(C)CCc2c(c(C)c(C)c(O)c2C(C)C=CCC(C)C)O1</smiles>

$80 \%$

Table 2. Synthesis of fatty acid conjugates by Claisen-rearrangement. 